\title{
The future of health economics: The potential of behavioral and experimental economics
}

\author{
FREDRIK HANSEN ${ }^{1}$ \\ ANDERS ANELL ${ }^{2}$ \\ ULF-G. GERDTHAM ${ }^{1,3}$ \\ CARL HAMPUS LYTTKENS ${ }^{{ }^{*}}$ \\ ${ }^{1}$ Department of Economics, Lund University, Sweden \\ ${ }^{2}$ Department of Business Administration, Lund University, Sweden \\ ${ }^{3}$ Division of Health Economics, Department of Clinical Sciences, Lund University, Sweden
}

\begin{abstract}
Health care systems around the globe are facing great challenges. The demand for health care is increasing due to the continuous development of new medical technologies, changing demographics, increasing income levels, and greater expectations from patients. The possibilities and willingness to expand health care resources, however, are limited. Consequently, health care organizations are increasingly required to take economic restrictions into account, and there is an urgent need for improved efficiency. It is reasonable to ask whether the health economics field of today is prepared and equipped to help us meet these challenges. Our aim with this article is twofold: to introduce the fields of behavioral and experimental economics and to then identify and characterize health economics areas where these two fields have a promising potential. We also discuss the advantages of a pluralistic view in health economics research, and we anticipate a dynamic future for health economics.
\end{abstract}

JEL Classification: B40, C90, D03, I10

Key words: health economics, behavioral economics, experimental economics, pluralism

\section{Introduction}

Health systems around the world are facing similar challenges. Demand for health care is increasing due to the continuous development of new medical technologies, changing demographics, increasing and more diversified real income, and increasing expectations from patients. At the same time, there are only limited possibilities and willingness to expand health care resources through increased taxation or mandatory insurance. Consequently, there is an urgent need to find ways of improving efficiency in the health care sector.

An important question is to what extent the health economics of today is prepared and equipped to meet these challenges. Health economics was initially largely viewed as an applied field of economics, basically an application of neoclassical welfare economics, albeit with a close connection to the medical sciences. In 2000, on the first page of the introduction to the Handbook of Health Economics, Culyer and Newhouse could argue that: "By almost any criterion, health economics has been a remarkably successful sub-

* Correspondence to: Carl Hampus Lyttkens, Department of Economics, P.O. Box 7082, SE- 22007 Lund, Sweden. E-mail: carl_hampus.lyttkens@nek.lu.se 
discipline." Similarly, in a methodological analysis of health economics, Blaug (1998, p. S66), concluded that "there has been steady theoretical and empirical progress in health economics ever since 1970" but also noted that much of health economics research consisted of results from the US. Fuchs (2000) agreed that health economics had undergone a remarkable development but also argued in favor of developing a better understanding of economic behavior, especially through the incorporation of behavioral economics.

In the Nordic Journal of Health Economics, several recent articles suggest an expansion or refocus of today's health economics, especially in relation to the Nordic health care model. For example, Pedersen (2012) argues in favor of better accounting of the institutional structure of health care systems. According to him, we need a wider perspective covering non-market methods and resource allocation by a "public mechanism". ${ }^{1}$ Mooney et al. (2012) argue for non-market methods in a similar way, but specifically in favor of a communitarian perspective.

In line with Fuchs (2000), we focus in this article on how our understanding of health economics decision-making can be improved by considering methods, theories, and results from behavioral and experimental economics. We are still waiting for a major breakthrough of behavioral and experimental economics into health economics, such as those that have taken place in, for example, financial economics and game theory.

The aim of this article is twofold. The first aim is to present the relevant parts of behavioral and experimental economics. It is often argued that behavioral and experimental economics provide a better and more realistic account of individual economic decisionmaking compared to neoclassical economics. Our second aim is, consequently, to suggest the research potential that lies in an application of these two fields to a number of healtheconomic issues. However, this does not mean that all areas of health economics would necessarily benefit greatly from such an endeavor or that this is the only way forward in health economics.

This article is not intended to be a classical systematic review. Behavioral, experimental and health economics are three well-developed areas of economics. Reviewing frontier research in all three areas in a single article (including their interactions) is clearly impossible. Our more modest ambition is to introduce behavioral and experimental economics to the health economics researchers and to suggest a number of applications we believe are particularly promising. It is also beyond the scope of this article to address the issue of how these suggestions and insights relate specifically to the Nordic health care systems, not least in view of the considerable differences across and within the Nordic countries (Gerdtham, 2012; Iversen, 2011). However, we will have a fair amount to say about public health care systems which means the Nordic countries are indirectly in focus.

In some cases, straightforward applications of behavioral and experimental economics seem possible. In other cases, useful developments of behavioral and experimental economics in conjunction with health economics seem possible. For example, one important focus in this article will be the behavior of doctors, an area where it seems to us that relatively little theoretical or empirical progress has been made since McGuire's (2000) review. An increased understanding of what motivates and guides medical decisionmaking will likely enable us to increase efficiency in various health care systems.

The article is organized as follows. We start by introducing behavioral and experimental economics. We then note some of the particularly promising directions for health economics to develop in conjunction with behavioral and experimental economics.

\footnotetext{
${ }^{1}$ Pedersen (2012) does not believe that the application of behavioral economics will result in a new paradigm for health economics, but it is not completely clear what he means by "paradigm".
} 
Finally we make a few comments on methodological pluralism. We end with some general conclusions.

\section{Introducing behavioral and experimental economics}

This article distinguishes between behavioral and experimental economics, although they are often viewed as one and the same. Behavioral economics is essentially a theoretical approach, and those who engage in it often perform economic experiments in their empirical work. However, not all behavioral economists perform experiments, and experiments can also be performed by neoclassical economists. Some experimental economists are also critical of behavioral economic approaches and vice versa. For example, in 2002 the Nobel Memorial Prize in Economic Sciences was awarded to Vernon Smith (experimental economics) and Daniel Kahneman (behavioral economics). Interestingly, Smith (1991) has been critical of the work by Kahneman, and Kahneman has not been particularly influenced by methods and results from experimental economics.

\subsection{Behavioral economics ${ }^{2}$}

The last 30 years have seen a dynamic development in the theoretical representation of economic behavior. At the start of this period, the neoclassical approach was dominant. This is still an important approach, but parts of it are overshadowed by the development of behavioral economics. This latter approach can be described as the incorporation of methods and theories from cognitive psychology when specifically addressing individual economic decision-making. Despite heated debates between neoclassical and behavioral economists, much of the actual research performed can be viewed as complementary (Hansen 2012). Both parties address "behavior" but they often aim to explain different types of "behavior". For the behavioral economist, individual behavior at the micro level is usually the main interest. Neoclassical economists, on the other hand, often focus on aggregate outcomes such as market-level reactions. The assumption of a utility-maximizing individual is then primarily used as a stepping-stone and is of no particular interest in itself.

The neoclassical theory of economic behavior is, in the words of DellaVigna (2009, p. 315), "simple and powerful". At the same time, it also has limitations, which are often related to the assumptions made. DellaVigna (p. 315) describes some of these assumptions as follows:

Individuals make choices so as to maximize a utility function, using the information available, and processing this information appropriately. Individuals' preferences are assumed to be time-consistent, affected only by own payoffs, and independent of the framing of the decision.

The strategy of behavioral economists is basically to de-idealize these statements. DellaVigna distinguishes three major deviations from standard neoclassical models:

- non-standard preferences

- non-standard beliefs

- non-standard decision-making

To begin with, preferences are much more complex than assumed by neoclassical economics. For example, they tend to be time inconsistent, as shown by Loewenstein in his work on inter-temporal choices (see the overview in Frederick et al., (2002)). Our

\footnotetext{
${ }^{2} \mathrm{Cf}$. DellaVigna (2012) for further references to this literature.
} 
preferences also tend to be reference-dependent (i.e., a status quo bias), and we value gains and losses differently in relation to the reference point (often known as loss aversion). This is captured in the well-known prospect theory of Kahneman and Tversky (1979) and its later extension by the same authors (Tversky and Kahneman, 1992). One consequence of reference-dependence is known as the endowment effect, which suggests that a person values a good more highly if it is among his possessions. Another characteristic of prospect theory is the diminishing sensitivity of the value function and probability weighting with a tendency to overweigh small probabilities. Finally, we are, in fact, not purely self-interested, and we frequently take the interests of others into account, although not necessarily in a way that is to the advantage of these other people. This is described as the social preference approach and was mainly developed by Fehr (see, e.g., Fehr and Gächter, 2000), involving concepts such as altruism, reciprocity and inequality aversion. ${ }^{3}$

Second, beliefs are not correct on average, in contrast to the usual assumption in the neoclassical approach. ${ }^{4}$ We are all, more or less, overconfident about our abilities and about time; we are often too optimistic, also known as the planning fallacy. We often conclude from too-small samples. There is furthermore no guarantee that the feedback we receive on our decisions helps us develop more accurate beliefs. Finally there is projection bias, which means we tend to expect our future preferences to be close to our present ones. This is, for example, an important issue for health economists who ask individuals about their hypothetical future states of happiness and health. Projection bias also has clear relevance for situations where the individual makes inter-temporal choices that affect her health. This is a very common feature in health economics studies and an area where behavioral economics has much to contribute. To the extent that we fail to consider this and other issues raised by behavioral economics, the reliability and validity of many health economics studies can be challenged.

Finally, non-standard decision-making means we do not make decisions as assumed by neoclassical economics, i.e., there are limits to rationality and the search for optimal solutions to complex problems. Framing, or the way the different choice alternatives are presented, is an interesting and relevant area. In the neoclassical approach, framing should not matter, but the entire business of marketing implies that presentation is vital. Related to framing (and indeed marketing) is the fact that we are also affected by persuasion, social pressure, and emotions. Furthermore, we frequently follow our habits rather than making explicit choices (Lindbladh and Lyttkens, 2002). To this end, we use different heuristics (rules of thumb) both when we search for information and when we decide. This idea goes back to Simon's $(1955 ; 1956)$ work on bounded rationality, where reference-dependence also plays a vital part. Given our cognitive limitations (ignored in neoclassical economics) we can only devote limited resources to a problem of choice. Many different heuristics have been presented, among them the well-known concept of "satisficing". There have been some attempts at modelling this type of procedure as successful (cf., e.g., Gigerenzer et al., 1999), while other attempts have focused more on less successful decision-making (Gilovich et al., 2002).

Health economics is still at an early stage of applying theoretical approaches and empirical results from behavioral economics, particularly compared to financial economics. For example, in the recent Oxford Handbook of Health Economics (Glied and Smith, 2011), "behavioral economics" is only mentioned briefly in the chapter on addiction. ${ }^{5}$ On the other

\footnotetext{
${ }^{3}$ Cf., e.g., Andreoni (1990) and Rabin (1993).

${ }^{4}$ Cf. DellaVigna (2012) and references therein.

${ }^{5}$ The present article does not address behavioral and experimental economics perspectives on addiction and risky behavior, which are already nicely covered in Cawley and Ruhm (2012) and Kenkel and Sindelar (2011).
} 
hand, the Handbook in Health Economics, Volume 2, by Pauly et al. (2012), includes several chapters dealing with behavioral economics theories and results, especially the contribution of Chandra et al. (2012) regarding possible explanations of the variations in doctors' treatment choices.

The former Director of the US Office of Management and Budget, Peter Orszag (2008), has emphasized the need for a behavioral economic perspective on health care in order to improve the decision-making of both doctors and patients. A review of medical decision-making (Chapman, 2009, p. 600) concluded that "the study of decision processes is not just an academic exercise - decision phenomena such as risk preferences, time preferences, and biases have been shown to be related to real-world medical decisions and health behaviors."

A few interesting attempts have been made to improve the interaction between behavioral and health economics. Frank (2007) presents promising future directions, but most of them are best classified as modifications of the neoclassical approach. Frank also mentions, however, the need to take account of professional norms and stereotyping heuristics. In a comment to Frank, Glazer (2007) lists the following non-standard factors related to doctors' decisions: small samples, uncontrolled experiments, extreme cases, stereotypes, common practice, the need to "do something", and the patient's expectations.

The decision environment facing the doctor is not an easy one (Frank, 2007; Frank and Zeckhauser, 2008). Important decisions have to be made, despite important uncertainties and shortage of time for decision-making. However, it seems that doctors have developed efficient decision procedures to confront these conditions. Unpacking how these decisions are made, and their health and economic consequences, is a key challenge for future research. According to Frank and Zeckhauser (2008), doctors have managed the four "costs of customization" - communication, cognition, coordination, and capability - mainly by developing professional norms or heuristics. Professional norms and, therefore, the heuristics and behavior of professionals, can be strongly influenced by respected leaders. They are therefore often of a local nature and may result in "small area variations" (Glazer, 2007).

Doctors also display non-standard beliefs. A survey in Chicago showed that doctors are often too optimistic in their prediction of patient survival, especially when communicating with the patients and their relatives (Alexander and Christakis, 2008). Interestingly, the authors succeeded in incorporating their survey into the administrative forms, which a doctor had to complete anyway when diagnosing a patient. Gigerenzer et al. (2008) focus on the difficulties that patients, medical journalists, and doctors have in understanding and communicating probabilities. Patients and medical journalists in general are "statistically illiterate", and serious consequences may emerge if the doctor cannot communicate the pros and cons of different treatments. ${ }^{6}$

We end this overview with three recent developments in behavioral economics. Conflict of interest (COI) has been addressed by Dana and Loewenstein (2003), with conflict between professional interest and financial incentives in the USA as an example. Such conflicts are often accompanied by an unconscious self-serving bias, and at the moment, we do not know how to address this. According to Dana and Lowenstein, the policies in use are based on the assumption that COI is a deliberate choice, and the efficiency of these policies is consequently doubtful.

\footnotetext{
${ }^{6}$ The authors suggest using frequencies instead of probabilities in communication with patients. There is an interesting similarity between the suggestion of Gigerenzer et al. (2008) and "the number needed to treat (NNT)" that is often used in the communication of results from clinical research between doctors (Laupacis et al., 1988).
} 
One way to affect health behavior is to use "nudges" (Thaler and Sunstein, 2008). Better knowledge about people's decision-making will enable the development of policies intended to make small changes in the decision situation; that is, to push (or nudge) people in a certain direction in their decision-making. Typical examples of health-related nudges are serving alcohol in smaller glasses and making carrots the default side order instead of chips.

A middle ground between the behavioral and neoclassical views of individual decision-making is the dual-process approach (Stanovich and West, 2000). Two systems are at work when we decide: the intuitive system and the analytical system. In our everyday decisions, the intuitive system is at work, and in uncommon, strategic situations, the analytical system takes over. However, the latter does not always happen. When the intuitive system is used for decisions that actually demand more analytical reasoning, biases might result. Croskerry (2009) presents a dual-process model of doctors' decision-making which covers all steps and the extent to which intuitive and analytical reasoning operates at the different stages. According to Croskerry, pattern recognition connects the two types of reasoning.

\subsection{Experimental economics}

Health economists were prominent in the famous large-scale RAND health insurance experiment that took place roughly forty years ago (Aron-Dine et al., 2013). Today, a very popular class of experiments among health economics is stated-preference experiments, especially so-called discrete choice experiments, which are often performed to elicit the willingness-to-pay of the participants in relation to a certain good. Such experiments are presumably well-known to most readers of this journal. Here, we will focus on two other types of experiments. The first type is the incentivized revealed-preference experiment. The second is experiments focusing on the judgment and decision-making phases preceding the actual choice of the participant.

We currently have a much more dynamic view on experiments than once expressed in the well-known Handbook of Experimental Economics by Kagel and Roth (1995). The proposed characterization by Harrison and List (2004, p. 1013f) is a good starting point, although, as these authors note, any taxonomy in a developing area should be used with caution. The article is ostensibly about field experiments, but in practice it covers more than that. To Harrison and List, a conventional laboratory experiment is characterized by a subject pool of students, abstract framing, and an imposed set of rules. In an artefactual field experiment, a nonstandard subject pool is added. In a framed field experiment, a field context is added. In a natural field experiment, the decision environment is familiar to participants to the extent that they are unaware that they are participating in an experiment. Harrison and List also describe a social experiment as the evaluation of governmental agencies through initiated variations in their policies, such as the RAND experiment mentioned above, and a natural experiment as the observation of a naturally occurring controlled comparison. ${ }^{7}$

In a recent reflection on the experimental method in economics, Bardsley et al. (2010) criticize the characterizations of Harrison and List (2004), especially in relation to the issue of external validity, i.e., to what extent the results of an experiment can be generalized. More specifically, they criticize the tendency of Harrison and List to apply a too strict model-like view on the interactions in experimental design. Instead, they encourage readers interested in the issue of external validity of experiments "to think outside

\footnotetext{
7 The authors also briefly discuss thought experiments and neuro-economic experiments. Interestingly, the currently popular web-based experiments are not mentioned at all.
} 
the rather limited 'box' of currently standard designs" (Bardsley et al. 2010, p. 242). The issue of external validity, as well as internal validity, together with the issues regarding the role of deception and the use of monetary incentives in experiments is part of a vibrant and ongoing methodological discussion in experimental economics (e.g., Guala, 2005; Bardsley et al., 2010).

The reader should note that according to Harrison and List (2004), financial incentives are not a necessary part of an experiment". In practice, however, financial incentives have largely been viewed as a mandatory part of this type of experiment. Following Buckley et al. (2012, p. 714), we describe typical laboratory experiments as incentivized revealed-preference experiments. ${ }^{8}$ That is, typical laboratory experiments (including strategic games) use an incentivized setting for their experiments and collect data of the actual choices made by the participants of the experiment.

The second experiment type we highlight is experiments that target the judgment and decision-making phases. These are closely related to the experimental procedure of cognitive psychology. Compared to incentivized revealed preference experiments, their structure is less formal, and the context often less controlled, financial incentives are not necessary (if they are not of specific interest), and even deception is sometimes used. These differences in experimental procedures probably harken from the different views on theory building between cognitive psychology and neoclassical economics (Ariely and Norton, 2007).

Some health economists may be surprised to hear that incentivized revealedpreference studies do not necessarily involve a representative participant pool and see no problems in relying on only students as participants. ${ }^{9}$ It depends on the purpose of the experiment, and, as argued by Falk and Heckman (2009, p. 537): "For the purpose of testing theories, this is not a problem because most economic models derive predictions that are independent of assumptions concerning participant pools." On the other hand, if the purpose is to directly address the economic reality, representativeness plays an important role when examining the external validity of the experiment. This may obviously be important in health economics.

Another interesting observation is that there seems to be very little interaction between experimental economists (typically performing incentivized revealed preference experiments) and health economists using stated preference methods, of which discrete choice experiments (DCEs) are the most popular in health economics at the moment. ${ }^{10} \mathrm{DCE}$ studies focus on the attributes connected to a specific choice situation. Choice sets are carefully designed and then tested on respondents; conclusions are drawn regarding the priorities and (indirectly) valuations of the different attributes (De Bekker-Grob et al., 2012). DCEs are often performed by mail or on the internet. Compared to earlier stated preference WTP studies, the DCE method is more structured and can be viewed as a nonincentivized revealed preference experiment. There is clearly potential for a dynamic interaction between the representatives of DCEs and experimental (and behavioral) economics. Among the issues that could usefully be addressed is the degree of control in experiments, the artificiality of the decision situation, the incentive structure, and whether participants use heuristics to make their choices. ${ }^{11}$

\footnotetext{
${ }^{8}$ Buckley et al. (2012, p. 714) also use the term "incentivized revealed-choice experiment".

${ }^{9}$ It is also common to use students as participants in experiments examining judgment and decision-making.

${ }^{10}$ A reasonable question is why there is so little interaction between these types of economists. One could guess, but a proper answer would need a methodological analysis of its own.

11 There is a debate among DCE economists about how many choice sets the respondents can manage without causing too much of a cognitive burden (Bech et al., 2011).
} 
Most behavioral economists are critical of WTP studies (see, e.g., Kahneman and Knetsch, 1992). For example, the endowment effect we have mentioned earlier can be used to explain the difference between WTP and willingness to accept (WTA) - a person places a higher value on what they already own. In fact, the endowment effect can be viewed as a general critique of valuation studies that use hypothetical questions. However, we agree with Kling et al. (2012) that a well-thought-out and well-performed WTP study can be informative and important, perhaps especially in health economics. ${ }^{12}$ Kling et al. (2012) also address the fundamental dilemma, basically an example of the well-known Duhem-Quine thesis, that if the outcome of a mainstream-economics study displays behavioral economic tendencies, it is difficult to tell whether this is due to the data collection process, a failure of the underlying neoclassical theoretical assumptions, or both. Stated preference economists tend to believe only in the former possibility, and unfortunately do not take the latter possibility into account. This is an area where an increased interaction between stated preference economists and behavioral economists can be advantageous and seem reasonable to strive for.

Although we have chosen to highlight two types of experiments, it is important to note that the combination of different types of experiments (as well as other empirical methods) is to be preferred when examining an economic phenomenon. Different types of experiments are often complementary. Falk and Heckman (2009, p. 537) argue: "Field data, survey data, and experiments, both lab and field, as well as standard econometric methods, can all improve the state of knowledge in the social sciences."

Economic experiments are rarely performed on doctors; an alternative is to use medical students as participants. ${ }^{13}$ For example, Henning-Schmidt et al. (2011) performed a laboratory experiment on payment systems in which medical students were confronted with different payment structures and asked to make decisions as doctors on medical services provided to patients. The participants' decisions were affected by the payment structure. For example, 33\% less medical services were supplied under capitation than under fee-for-service, as suspected from a theoretical point of view. The authors described laboratory experiments in health economics as being in their infancy but also as having the potential to provide vital information. For example, an experiment could function (p. 639) "as a 'wind tunnel' before institutional changes are implemented, e.g., before the implementation of a health care reform". ${ }^{14}$

\section{Promising directions in health economics}

The discussion above on behavioral and experimental economics highlighted some interesting attempts to introduce both fields into health economics. If we take a bird's eyes view of health economics, several areas suggest themselves as being highly important in the coming decades while at the same time being areas where behavioral and experimental economics have much to offer - either as straightforward applications or as a source of inspiration.

As mentioned above, the major advantage of behavioral economics is that it is superior to neoclassical economics when accounting for decision-making by individuals and, in some cases, by groups. We focus here mainly on doctors but will also comment on other health care professionals, on patients, and on the relative of patients. The doctor is the

\footnotetext{
${ }^{12}$ Mooney et al. (2012, p. 120) note that health economists have been relatively slow to respond to the critique of WTP studies compared to, for example, environmental economists.

${ }^{13}$ Fan et al. (1998) is an early example.

${ }^{14}$ A similar experimental setting was used by Godager et al. (2013) in a recent study on how performance disclosure affects doctors' medical decisions.
} 
key decision-maker in health care and in many ways determines both the health outcome for the patient and health care costs. Thus, understanding doctor behavior and how it interacts with other agents and the organizational structure is fundamental in an analysis of what is produced, how and by whom. ${ }^{15}$

We need to better understand the motivation for doctors, particularly in situations where financial incentives are of relatively little importance. In various health care systems, we find doctors who are salaried employees, and a straightforward application of the models developed for market-systems would imply that these doctor would expend little if any effort. A brief contact with the realities of, for example, public hospitals with employed doctors shows this to be false, and we need to investigate what motivates doctors under such circumstances and not least what causes the substantial variations in effort across doctors.

The dominant neoclassical approach focuses, among other things, on the doctor's ability to exploit their information advantage for personal gain, and doctors are regarded either as utility maximizers or as profit maximizers (McGuire, 2000). Although it is reasonable to believe that health care providers are affected by some degree of self-interest and financial incentives, it is obvious that this is not their only motivation. Decisions are generally guided by multiple motives, and there are several cases in which financial motives are crowded out by cultural, moral, and career-related motives (Gneezy et al., 2011), aspects that are typically addressed in behavioral and experimental economics. ${ }^{16}$

One important aspect of this is that health care production often entails working in teams across medical specialties and occupations. In teams, doctors interact with other health care professionals (other doctors, nurses, physiotherapists, administrators). Multidisciplinary teamwork is a necessity in modern health care organizations, but little is known about the underlying mechanisms of such teamwork (Bosch et al., 2009). The motives of the participants in team production are not well understood. Surveys can be used to examine mechanisms and individual motives in the initial phase of this research (Abernethy and Stoelwinder, 1994), but economic experiments are also appropriate. Aspects of interest include the role of the disciplinary residence of the participants and the interaction between doctors with different fields of specialization (Anell, 2004). With behavioral economic perspectives, we are likely to be able to better account for the different motives of the participants in teamwork (e.g., career-related, cultural, moral, disciplinary based, financial), and can structure these teams more efficiently in relation to both economic and health care outcomes.

The setting for the teamwork also seems to make a difference and should be accounted for in theory and experiments. Available information suggests that teamwork can be quite efficient in the temporary organization that is established when a patient is admitted to the emergency room. In other cases, such as teamwork around frail elderly people in outpatient settings, it is more difficult to establish the communication, coordination, and collaboration needed to provide good quality care (Anell \& Glenngård, 2014). Understanding teamwork will help us look into the black box of coordination and collaboration both inside and outside of hospitals.

The importance of team production seems likely to increase in the future with increasing sub-specialization. A crucial condition for team production will be the level of trust between the actors involved. It has long been recognized that, in principle, trust is an

\footnotetext{
${ }^{15}$ That the doctor has the greatest impact on health care consumption has important implications for policy. For example, cost sharing is usually more effective when applied on the supply-side; see, e.g., Trottmann et al. (2012).

${ }^{16}$ Somewhat paradoxically, altruism, such as the caring externality often mentioned in health economics, can, in neoclassical economics, take the form of self-interest (your utility enters my utility function).
} 
important element in most economic transactions including health care (Arrow, 1963), but it is with behavioral and experimental economics that trust and trustworthiness have become an important area of experimental empirical research. We are beginning to understand, for example, how trust and trustworthiness in a situation vary with the characteristics of the person one is confronted with (e.g., the person's age or gender). The level of trust is obviously also of fundamental importance in the doctor-patient relationship (cf. below). Incentivized revealed preference experiments can be used to study trust both between and within different professions.

In the study of teamwork, both surveys and DCEs can be used to study participant preferences and priorities. Bech (2003) performed a DCE on the hospital-related priorities of politicians and hospital managers and were able to detect minor but still interesting disparities.

Other agents in the hospital organization are often viewed from a neoclassical perspective (Barros and Olivella, 2011) and behavioral economic perspectives on organizations are not a well-developed field at the moment. Jan (2003) suggests that executives and politicians face a complex reality in their capacity as decision-makers of health care organizations. Decisions to reorganize activities or change the allocation of resources usually meet strong resistance from the medical professions that lose resources or influence. Such resistance results in high personal costs for decision-makers. This may cause politicians and executives to become reluctant to get involved in decisions that are too difficult, resulting in a bias towards the status quo and a situation where only marginal changes in the resource allocation can be managed. ${ }^{17}$

Medical decision-making, i.e., doctors decisions related to diagnostic tests and treatment options is a challenging and underdeveloped research area. In a recent review on doctors' treatment choices (Chandra et al., 2012), the variations were still largely unexplained after applying the available (neoclassical) models, and the authors suggested turning to what they called "situational factors", which coincides at least in part with the ideas of behavioral economics. In line with these ideas, the "Hyper-Q" survey was performed between 2002 and 2005 in Swedish primary health care. The data collected mostly concerned patient choices and attitudes, but some primary healthcare doctors also participated. Based on this survey, Journath et al. (2008) showed that for hypertensive patients, the sex of the doctor and the patient had an effect on the treatment that was decided by the doctor. Female doctors were more successful in their treatment, especially concerning female patients. However, the authors did not address the health economics consequences of these differences in treatment.

There are several phenomena of interest in regard to doctors' decision-making. We will distinguish between issues related to the diagnosis phase and those related to the decision environment. ${ }^{18}$ The diagnostic decision can be further divided into the steps of gathering evidence, interpreting the evidence, and assessing probabilities, which is an interesting characterization of this part of the decision-making process.

A relevant application of behavioral economics would be to study what types of heuristics are used by doctors when deciding upon a diagnosis, and the related consequences, especially which biases these decisions reflect. The interaction between professional norms and heuristics need to be studied. Examining the heuristics used by doctors is a difficult task, but there is a shortcut by drawing on the related field of medical

\footnotetext{
${ }^{17}$ On this issue, cf. Coast (2001). A related interesting area is the impact of competition on management quality; see, e.g., Bloom et al. (2010).

18 The structure presented here coincides to a great extent with that presented in Eisenberg's (1979) classical article on medical decision-making; this was unintentional.
} 
decision-making. ${ }^{19}$ Among several interesting results, André et al. (2002) used focus groups to show that Swedish doctors use heuristics in their profession. However, they did not specify any of these heuristics, nor did they discuss their medical or economic implications. Bornstein and Emler (2001) presented different types of biases that might occur if heuristics are used inappropriately in medical decision-making. The biases mentioned in that study are much in line with the work by Kahneman and Tversky (e.g., representativeness, availability, framing), and the authors focus solely on the potential existence of these biases and do not report any data of their own. They also do not take the whole decision-making process of doctors into account, focusing instead on deciding upon a diagnosis and choosing a course of treatment.

A potentially fruitful approach would be to combine the characterization of Bornstein and Emler (2001) with the reference-dependent approach of Tversky and Kahneman (1992) and the dual-process model of Croskerry (2009). A recent review of prospect theory in economics argues that health economics is an area where prospect theory has potential (Barberis, 2013).

When we empirically investigate the decision-making of doctors (and/or medical students), a combination of economic experiments is preferred. Surveys, as well as interviews and the use of focus groups, can be a very illuminating first step because we are moving in largely unexplored territory and need to know more about how doctors make decision and the structure of their decision environment. DCEs as well as surveys are useful when the goal is to discover more about the priorities of doctors (Carlsen et al., 2012). For example, Pedersen et al. (2012) examined GPs' knowledge of patients' preferences and reached the conclusion that it is quite poor. Troëng (1997) et al. found that surgeons only occasionally asked patients about their preferences before giving advice on treatment.

To perform economic experiments on doctors' decision-making, it is again a good idea to take a look at the experimental procedures used in the field of medical decisionmaking. The most common procedure is to display videos of "patients" (played by actors) and then examine the decisions of participating medical students who are asked to make decisions as doctors regarding diagnosis, treatment, and prognosis (see, e.g., McKinlay et al., 1996; Aberegg and Terry, 2004). These types of experiments are likely to focus on the judgment and decision-making phases. A methodological challenge for such experiments is obviously the Hawthorne effect, i.e., that participants change their behavior because they know that they are being studied. This problem is difficult to avoid, but there have been attempts to address it statistically (Leonard, 2008).

With these latter areas of investigation, we have arrived at the doctor-patient relationship. This relationship is under rapid change due to the availability of medical information on the internet, ageing populations, and the consequent growing proportion of chronically ill patients. These developments will likely affect the degree of trust in the doctor-patient relationship and the patients' compliance with treatments. Communication between the parties will remain essential for the outcomes of the meeting between the doctor and her patient, but biases and/or misunderstandings can easily occur, especially when the probabilities are communicated and both doctor and patient may employ heuristics, although not necessarily of the same kind. ${ }^{20}$ In the case of elderly patients with multiple

\footnotetext{
${ }^{19}$ Behavioral economics and the field of medical decision-making are obviously related, but the latter does not always incorporate economic perspectives. However, the two fields are increasingly interacting: the theme for the 2011 annual conference of the Society for Medical Decision Making was "From Evidence to Decision Making: Role of Behavioral Economics in Medicine".

20 See, e.g., Köszegi's (2003) behavioral economics model of patient decision-making where the patient's fears and anxiety about the future enter as determinants of patient behavior.
} 
needs, the risk structure is likely to be complicated. Overall, efficient communication of risk information is of high priority. As noted above, Gigerenzer et al. (2008) suggest the use of frequencies instead of probabilities. Harmsen et al. (2013) instead support risk communication in the form of "prolongation of life".

As hinted above, it is interesting to examine the extent to which guidelines can be used to prevent biases, especially in relation to unwarranted inequalities. We refer to guidelines that are close to decision algorithms and are typically used to classify patients as high or low risk on the basis of a few questions about age, gender, weight, blood pressure, and so on. These guidelines are related to the behavioral economic approach of "nudge" frequently used in the USA (see above and, e.g., Aberegg and Terry, 2004; Wegwarth et al., 2009). To our knowledge, the efficient use of such guidelines in Sweden has not yet been evaluated; it would be worth analyzing the extent to which such guidelines can be used to improve doctors' decision-making.

In general, behavioral and experimental economics may yield important insights into the causal mechanisms underlying socioeconomic inequalities in health. While the study of such inequalities is one of the most dynamic fields in health economics at present, much of the literature focuses on associations among health, income, education, and labor market status, etc., without really considering the causal mechanisms (e.g. Smith 1999; Deaton 2002; Cutler et al., 2008; Case and Paxson, 2011). ${ }^{21}$ By using experiments, the decisionmaking of individuals in health-related behaviors can be isolated which is very difficult using non-experimental observational data.

Returning to the issue of financial incentives and provider reimbursement, we note that these issues have been the focus of much work in the neo-classical tradition. Nevertheless, the traditional empirical approach is limited by the forms of reimbursement that we can actually observe in the market or in existing organizations. Experimental economics can greatly extend the research agenda. As indicated in recent review articles, there is no known superior payment system; all have their advantages and disadvantages (e.g., McClellan, 2011; Christianson and Conrad, 2011). The available data are not particularly impressive and are mostly in the form of aggregate data before and after a change has occurred in a given payment system. It is often relatively easy to specify the financial incentive of a payment system. However, doctors are also affected by other types of motives and the interaction among different types of motives can be a complicated matter. Behavioral economics, accompanied by appropriate economic market experiments, have the capacity to clarify this picture of the different motives that are present alongside a certain payment system, and how this system affects the decision-making of doctors.

One particularly promising field of research focuses on the effects of pay-forperformance mechanisms. As suggested by Bevilacqua and Singh (2009), pay-forperformance may be a Pandora's Box that incentivizes emotional responses based on fear and greed rather than what is efficient and rational from a general perspective. The same mechanisms of extrinsic rewards may also crowd out professional norms and intrinsic motivations in an unwanted way (Gneezy et al. 2011). Again, policies in the field may strongly benefit from studies that take doctors' behavior into account.

Similarly the "experiment" with quasi-markets in the UK is highly interesting for many countries, because they may signal possibilities of combining public production with competition among providers. Once again however, we are severely constrained if we have to rely only on the natural experiments that have in fact taken place. The main advantage of performing economic experiments is that we can better examine the decision-making of individuals (both in relation to reality and theory), and we can also set up various market

21 Some notable exceptions are Gerdtham et al. (2015) and Fleurbaey and Schokkaert (2012). 
structures and examine their outcomes. ${ }^{22}$ Testing (experimental) markets will be an important input into the complicated issue of developing appropriate payment systems. More studies like that of Henning-Schmidt et al. (2011) should be performed to test the possible alternatives and combinations of payment systems. ${ }^{23}$ A key challenge will also be to make the decision environment less artificial.

In particular in view of the ageing populations, the role of the relatives of patients is worthy of greater attention. Sometimes relatives act as surrogate decision-makers. This is an area of intense research in other disciplines, and it has been found in economic experiments that "taking risks on behalf of others" leads to a lower degree of loss aversion (Andersson et al., 2013).

Furthermore, relatives can be carriers of conflict of interests. The allocation of the costs of treatment and rehabilitation between the relatives of the patient and the provider of health care or nursing home care is often the object of bargaining. With an ageing population, an increasing amount of this care will be pushed towards the informal care sector (e.g., relatives), but there will be resistance to this development, most likely with important social differences. Obviously the relatives may feel a conflict between their own interests and the welfare of their elderly relative, possibly with gender differences.

\section{Pluralism and health economics}

In this article, we have already indicated our support for a pluralistic view of health economics in view of the challenges of the future and the research potential of behavioral and experimental economics.

Economists often use the term "paradigm" but it is often unclear whether they are using it in the original Kuhnian (1962) sense. A rather common methodological belief among practicing economists seems to be that economics as a scientific discipline should apply only one theoretical approach. The risk then arises that the concept "paradigm" is used in a prescriptive manner rather than descriptively in the Kuhnian sense of reflecting the historical development of a discipline. Just because the neoclassical approach has been dominant in economics, it does not follow that such a dominant position is relevant and useful for the future. On the contrary, Davis (2008) shows that dominant approaches are often followed by a pluralistic phase, and the current trends in economics are no exception. At the moment, we have several interesting approaches besides the neoclassical, and most of them complement each other from the perspective of capturing different parts of the economic reality (Hansen, 2013). We support this type of pluralism in theoretical approaches but also in regard to empirical methods and economic methodology. ${ }^{24}$

Our discussion above should not be taken to imply that the neoclassical approach to health economics is refuted or should be abandoned. On the contrary, it has done a great job on many accounts. However, all theoretical approaches will have both strengths and limitations. By applying behavioral economics we will first of all be able to provide a better model of individual decision making. Both Blaug (1998) and Hodgson (2009) find it strange that there have been so few attempts to apply alternative economic approaches to health and health care. Other useful approaches include institutional economics (North, 1990), which overlap with behavioral and experimental economics.

\footnotetext{
${ }^{22}$ A related field is insurance behavior. Recent examples of experimental studies of insurance behavior are Schram and Sonnemans (2011) and Krieger and Felder (2013), as well as Finkelstein et al. (2012) for a field setting.

23 See also Brosig-Koch (2013a, 2013b).

24 We will not address the more methodologically complicated issue of explanatory pluralism (see, e.g., Marchionni, 2007), although it is an interesting issue in relation to health economics.
} 
A pluralistic view can also be usefully applied to empirical methods. For example, when studying health inequality measurement, a combination of register, survey, and experimental data could be applied. A more systematic development and use of register data would be very useful. For example, the MABEL data base in Australia contains a longitudinal survey of currently 10500 Australian doctors (Joyce et al., 2010). We would suggest that something similar should be attempted on a Nordic basis.

Finally, it is also worth considering a flexible approach to economic methodology. ${ }^{25}$ We should be open to views on scientific methods other than those typically held in health economics. For example, the different agents in a work team often have different disciplinary backgrounds, and it would be interesting to examine how this affects their abilities to communicate and cooperate in a team. These types of studies are close to the methodological approach of social studies of science, exploring, for example, how scientific results regarding health care markets are used by the actors in that same market. ${ }^{26}$

\section{Conclusion}

Health economics has been a successful sub-discipline of economics. However, we are now facing serious challenges in the development of a health care system for the future. To successfully meet these challenges, health economics researchers need to consider new theoretical, empirical and methodological approaches. In this article we have singled out behavioral and experimental economics as interesting alternatives worth considering. With behavioral economics, we can better account for individual decision-making by doctors, nurses, administrators, patients and their relatives, and even administrators and politicians. By performing economic experiments, we can better study the decision-making of individuals as well as market outcomes. With a pluralistic view, we believe health economics and health economists face a bright future. We look forward to participating in this continued journey.

\section{Acknowledgements}

We are grateful to Terence Chen, John B. Davis, Mandy Ryan, Erik Wengström and two anonymous referees for valuable suggestions and comments on an earlier version of this article. Financial support from Rådet för kommunalekonomisk forskning och utveckling (KEFU) is gratefully acknowledged. The Health Economics Program (HEP) at Lund University also receives core funding from FAS (dnr. 2006-1660), the Government Grant for Clinical Research (ALF), and Region Skåne (Gerdtham).

\section{References}

Aberegg, S. K. and Terry, P. B. (2004). Medical decision-making and healthcare disparities. Journal of Laboratory and Clinical Medicine, 144(1): 11-17.

Abernethy, M. A. and Stoelwinder, J. U. (1994). The role of professional control in the management of complex organizations. Accounting, Organizations and Society, 20(1):1-17.

\footnotetext{
${ }^{25}$ Methodological pluralism is a complex matter (Dow, 2007), and we do not mean to imply that "anything goes".

${ }^{26}$ Cf., e.g., MacKenzie (2006) who studies how financial traders use the results and theories of financial economics in their everyday work.
} 
Alexander, M. and Christakis, N. A. (2008). Bias and asymmetric loss in expert forecasts: a study of physician prognostic behavior with respect to patient survival. Journal of Health Economics, 27: 1095-1108.

Andersson, O., Holm, H. J., Tyran, J.-T. and Wengström, E. (2013). Deciding for others reduces loss aversion. Unpublished ms, Lund University.

André, M., Borgquist, L., Foldevi, M. and Mölstad, S. (2002). Asking for 'rules of thumb': a way to discover tacit knowledge in general practice. Family Practice, 19: 617-622.

Andreoni, J. (1990). Impure Altruism and Donations to Public Goods: A Theory of Warm-Glow Giving. Economic Journal, 100(401): 464-477.

Anell, A. (2004). Närsjukvård - nya revirstrider eller patientorienterad vård? Läkartidningen, 101(14): 1310-1315.

Anell A. and Glenngård A. (2014) The use of outcome and process indicators to incentivize integrated care for frail older people. A case study of primary care services in Sweden. International Journal of Integrated Care, Oct-Dec, URN:NBN:NL:UI:10-1-114805.

Ariely, D. and Norton, M. I. (2007). Psychology and Experimental Economics: A Gap in Abstraction. Current Directions in Psychological Science, 16(6): 336-339.

Aron-Dine, A., Einav, L. and Finkelstein, A. (2013). The RAND health insurance experiment, three decades later. Journal of Economic Perspectives, 27(1): 197-222.

Arrow, K. (1963). Uncertainty and the welfare economics of medical care. American Economic Review 53: 941-73.

Barberis, N. C. (2013). Thirty years of prospect theory in economics: a review and assessment. Journal of Economics Perspectives, 27(1): 173-195.

Bardsley, N., Cubitt, R., Loomes, G., Moffatt, P., Starmer, C. and Sugden, R. (2010). Experimental Economics: Rethinking the Rules. Princeton: Princeton University Press.

Barros, P. P. and Olivella, P. (2011). Hospitals: teaming up! In S. Glied and P. C. Smith (Eds.), The Oxford Handbook of Health Economics (pp. 432-462). Oxford: Oxford University Press.

Bech, M. (2003). Politicians' and hospital managers' trade-offs in the choice of reimbursement scheme: a discrete choice experiment. Health Policy, 66: 261-275.

Bech, M., Kjaer, T. and Lauridsen, J. (2011). Does the number of choice sets matter? Results from a web survey applying a discrete choice experiment. Health Economics, 20: 273-286.

Bevilacqua, C. M. and Sing, P. (2009). Pay for performance - panacea or Pandora's Box? Revisiting an old debate in the current economic environment. Compensation \& Benefits Review, 41(5): 20-26.

Blaug, M. (1998). Where are we now in British health economics? Journal of Health Economics, 7: S63-S78.

Bloom, N., Propper, C., Seiler, S. and Reenen, J. V. (2010). The impact of competition on management quality: Evidence from public hospitals. Working Paper 16032, NBER Working Paper Series.

Bornstein, B. H. and Emler, A. C. (2001). Rationality in medical decision-making: a review of the literature on doctors' decision-making biases. Journal of Evaluation in Clinical Practice,7(2): 97-107.

Bosch, M., Faber M. J., Cruijsberg J., Voerman, G. E., Leatherman, S., Grol, R. P., Hulscher, M. and Wensing, M. (2009). Effectiveness of patient care teams and the role of clinical expertise and coordination. A literature review. Medical Care Research and Review, 66(6): 5S-35S.

Brosig-Koch, J., Henning-Schmidt, H., Kairies, N. and Wiesen, D. (2013a). How Effective are Payfor-performance Incentives for Physicians? A Laboratory Experiment. Working Paper, Ruhr Economic Papers, No. 413. 
Brosig-Koch, J., Henning-Schmidt, H., Kairies, N. and Wiesen, D. (2013b). How to Improve Patient Care? An Analysis of Capitation, Fee-for service, and Mixed Payment Schemes for Physicians. Working Paper, Ruhr Economic Papers, No. 412.

Buckley, N. J., Cuff, K., Hurley, J., McLeod, L., Mestelman, S. and Cameron, D. (2012). An experimental investigation of mixed systems of public and private health care finances. Journal of Economic Behavior \& Organization, 84: 713-729.

Carlsen, B., Hole, A. R., Kolstad, J. R. and Norheim, O. F. (2012). When you can't have the cake and eat it too: A study of medical doctors' priorities in complex choice situations. Social Science \& Medicine, 75: 1964-1973.

Case, A. and Paxson, C. (2011), The long reach of childhood health and circumstance: Evidence from the Whitehall II study. Economic Journal, 121(554): F183-F204.

Cawley, J. and Ruhm, C. J. (2012). The economics of risky health behaviors. In M. V. Pauly, T. G. McGuire and P. P. Barros (Eds.), Handbook in Economics, Health Economics vol 2 (pp. 95199). London: North-Holland.

Chandra, A., Cutler, D. and Song, Z. (2012). Who ordered that? The economics of treatment choices in medical care. In M. V. Pauly, T. G. McGuire and P. P. Barros (Eds.), Handbook in Economics, Health Economics vol 2 (pp. 397-432). London: North-Holland.

Chapman, G. B. (2009). The psychology of medical decision making. In D. J. Koehler and N. Harvey (Eds.), Blackwell Handbook of Judgment \& Decision Making (pp. 585-603). Oxford: Blackwell Publishing.

Christianson, J. B. and Conrad, D. (2011). Provider payment and incentives. In S. Glied and P. C. Smith (Eds.), The Oxford Handbook of Health Economics (pp. 624-648). Oxford: Oxford University Press.

Coast, J. (2001). Citizens, their agents and health care rationing: an exploratory study using qualitative methods, Health Economics 10: 159-174.

Croskerry, P. (2009). Clinical cognition and diagnostic error: applications of a dual process model of reasoning. Advances in Health Science Education, 14: 27-35.

Culyer, A. J. and Newhouse, J. P. (2000). Introduction: the status and scope of health economics. In A. J. Culyer and J. P. Newhouse (Eds.), Handbook of Health Economics, vol 1A (pp. 1-8). London: Elsevier.

Cutler D., Lleras-Muney, A. and Vogl T. (2008), Socioeconomic Status and Health: Dimensions and Mechanisms, NBER Working Paper No. 14333.

Dana, J. and Loewenstein, G. (2003). A social science perspective on gifts to physicians from industry. Journal of the American Medical Association, 290(2): 252-255.

Davis, J. B. (2008). The turn in recent economics and return of orthodoxy. Cambridge Journal of Economics, 32: 349-366.

Deaton A. (2002), Policy implications of the gradient of health and wealth an economist asks, would redistributing income improve population health? Health Affairs, 21, 13-30.

De Bekker-Grob, E. W., Ryan, M. and Gerard, K. (2012). Discrete choice experiments in health economics: a review of the literature. Health Economics, 21: 145-172.

DellaVigna, S. (2009). Psychology and economics: evidence from the field. Journal of Economic Literature, 47(2): 315-372.

Dow, S. C. (2007). Variety of methodological approach in economics. Journal of Economic Surveys, 21(3): 447-465.

Eisenberg, J. M. (1979). Sociologic influences on decision-making by clinicians. Annals of Internal Medicine, 90: 957-964.

Falk, A. and Heckman, J. J. (2009). Lab Experiments Are a Major Source of Knowledge in the Social Sciences, Science, 326(23): 535-538. 
Fan, C., Chen, K. and Kan, K. (1998). The Design of Payment Systems for Physicians under Global Budget - An Experimental Study. Journal of Economic Behavior and Organization, 34, 295311.

Fehr, E. and Gächter, S. (2000). Cooperation and punishment in public goods experiments. American Economic Review, 90: 980-994.

Finkelstein, A., Taubman, S., Wright, B., Bernstein, M., Gruber, J., Newhouse, J. P., Allen, H. and Baicker, K. (2012). The Oregon Health Insurance Experiment: Evidence from the First Year. Quarterly Journal of Economics, 127, 1057-1106.

Fleurbaey, M. and Schokkaert, E. (2012). Equality in health and health care. In M. V. Pauly, T. G. McGuire and P. P. Barros (Eds.), Handbook in Economics, Health Economics vol 2 (pp. 10031092). London: North-Holland.

Frank, R. G. (2007). Behavioral economics and health economics. In P. Diamond and H. Vartiainen (Eds.), Behavioral Economics and Its Applications (pp. 195-222). Princeton: Princeton University Press.

Frank, R. G. and Zeckhauser, R. J. (2008). Custom-made and ready-to-wear treatments: behavioral propensities in doctors' choices. Journal of Health Economics, 26: 1101-1127.

Frederick, S., Loewenstein, G and O'Donogue, T. (2002). Time Discounting and Time Preference: A Critical Review. Journal of Economic Literature, 40: 351-401.

Fuchs, V. R. (2000). The future of health economics. Journal of Health Economics, 19: 141-157.

Gerdtham, U.-G. (2012). Can health economics help us understand our strange public health care system? Nordic Journal of Health Economics, 1(1): 1-5.

Gerdtham, U.-G., Lundborg, P., Lyttkens, C. H. and Nystedt, P. (2015). Do socioeconomic factors really explain income-related inequalities in health? Applying a twin design to standard decomposition analysis. Scandinavian Journal of Economics. In Press.

Gigerenzer, G., Gaissmaier, W., Kurz-Milcke, E., Schwartz, L. M. and Woloshin, S. (2008). Helping doctors and patients make sense of health statistics. Psychological Science in the Public Interest, 8(2): 53-96.

Gigerenzer, G., Todd, P. M. and The ABC Research Group (1999). Simple Heuristics That Makes Us Smart. Oxford: Oxford University Press.

Gilovich, T., Griffin, D. and Kahneman, D. (Eds.) (2002). Heuristics and Biases: The Psychology of Intuitive Judgment. Cambridge: Cambridge University Press.

Glazer, J. (2007). Comment. In P. Diamond and H. Vartiainen (Eds.), Behavioral Economics and Its Applications (pp. 223-230). Princeton: Princeton University Press.

Glied, S. and Smith, P. C. (Eds.) (2011). The Oxford Handbook of Health Economics. Oxford: Oxford University Press.

Gneezy, U., Meier, S. and Rey-Biel, P. (2011). When and why incentives (don't) work to modify behavior. Journal of Economic Perspectives 25(4): 191-210.

Godager, G., Henning-Schmidt, H. and Iversen, T. (2013). Does performance disclosure influence physicians' medical decisions? An experimental analysis. University of Oslo, Health Economic Research Network (HERO), Working Paper 2013:1.

Guala, F. (2005) The Methodology of Experimental Economics. Cambridge: Cambridge University Press.

Hansen, F. (2012). In what way is behavioral economics realistic? Unpublished ms., Lund university.

Hansen, F. (2013). For theoretical pluralism in economic theory. In H. Corvellec (Ed.), What is theory? Answers from the social and cultural sciences (pp. 221-230). Copenhagen: CBS Press.

Harmsen, C. G., Jarbøl, D. E., Nexøe, J., Støvring, H., Gyrd-Hansen, D., Nielsen, J. B., Edwards, A. and Kristiansen, I. S. (2013). Impact of effectiveness information format on patient choice of therapy and satisfaction with decisions about chronic disease medication: The "Influence of 
intervention Methodologies on Patient Choice of Therapy (IMPACT)" cluster-randomized trial in general practice. BMC Health Services Research, 13:76.

Harrison, G. W. and List, J. A. (2004). Field experiments. Journal of Economic Literature, 42: 10091055 .

Henning-Schmidt, H., Selten, R. and Wiesen, D. (2011). How payment systems affect physicians' provision behaviour - an experimental investigation. Journal of Health Economics, 20: 637646.

Hodgson, G. M. (2009). Towards an Alternative Economics of Health Care." Health Economics, Policy and Law, 4: 99-114.

Iversen, T. (2011). Vägval $i$ vården - en ESO rapport om skillnader och likheter i Norden. Rapport till Expertgruppen för Studier i Offentlig Ekonomi nr. 2011:7.

Jan, S. (2003) Why does economic analysis in health care not get implemented more? Towards a greater understanding of the rules of the game and costs of decision-making. Applied Health Economics and Health Policy, 2(1): 17-24.

Journath, G., Hellénuis, M.-L., Manhem, K., Kjellgren, K. I. and Nilsson, P. (2008). Association of physician's sex with risk factor control in treated hypertensive patients from Swedish primary healthcare. Journal of Hypertension, 26: 2050-2056.

Joyce, C.M., Scott, A., Sung-Hee, J., Humphreys, J., Kalb, G., Witt, J. and Leahy, A. (2010) The "Medicine in Australia: Balancing Employment and Life (MABEL)" longitudinal survey Protocol and baseline data for a prospective cohort study of Australian doctors' workforce participation", BMC Health Service Research 10: 50.

Kagel, J. H. and Roth, A. E. (Eds.) (1995) The Handbook of Experimental Economics. Princeton: Princeton University Press.

Kahneman, D. and Knetsch, J. L. (1992). Valuing public goods: purchase of moral satisfaction. Journal of Environmental Economics and Management, 22(1): 57-70.

Kahneman, D. and Tversky, A. (1979). Prospect theory: An analysis of decision under risk. Econometrica, 47(2): 263-292.

Kenkel, D. S. and Sindelar, J. (2011). Economics of healthy behaviors and addictions: contemporary issues and policy implications. In S. Glied and P. C. Smith (Eds.), The Oxford Handbook of Health Economics (pp. 206-231). Oxford: Oxford University Press.

Kling, C. L., Phaneuf, D. J. and Zhao, J. (2012). From Exxon to BP: has some number become better than no number? Journal of Economics Perspectives, 26(4): 3-26.

Köszegi, B. (2003). Health anxiety and patient behavior. Journal of Health Economics, 22: 10731084.

Krieger, M. and Felder, S. (2013). Can Decision Biases Improve Insurance Outcomes? An Experiment on Status Quo Bias in Health Insurance Choice. International Journal of Environmental Research and Public Health, 10, 2560-2577.

Kuhn, T. S. (1962). The Structure of Scientific Revolutions. Chicago: University of Chicago Press.

Laupacis A., Sackett, D. L. and Roberts, R. S. (1988). An assessment of clinically useful measures of the consequences of treatment. New England Journal of Medicine, 318(26): 1728-1733.

Leonard, K. L. (2008). Is patient satisfaction sensitive to changes in the quality of care? An exploitation of the Hawthorne effect. Journal of Health Economics, 27: 444-459.

Lindbladh, E. and Lyttkens, C. H. (2002). Habit versus choice: the process of decision-making in health-related behaviour, Social Science \& Medicine 55: 451-65.

MacKenzie, D. (2006). An Engine, Not a Camera: How Financial Models Shape Markets. London: MIT Press.

Marchionni, C. (2007). Explanatory pluralism and complementarity: from autonomy to integration. Philosophy of the Social Sciences, 38(3): 314-333. 
McClellan, M. (2011). Reforming payments to healthcare providers: the key to slowing healthcare cost growth while improving quality. Journal of Economic Perspectives, 25(2): 69-92.

McGuire, T. G. (2000). Physician agency. In A. J. Culyer and J. P. Newhouse (Eds.), Handbook of Health Economics, vol 1A (pp. 461-536). London: Elsevier.

McKinlay, J. B., Potter, D. A. and Feldman, H. A. (1996). Non-medical influences on medical decision-making. Social Science and Medicine, 42(5): 769-776.

Mooney, G., Tinghög, G. and Kalkan, A. (2012). The need for a new paradigm in Scandinavian health economics. Nordic Journal of Health Economics, 1(2): 119-133.

North, D. C. 1990. Institutions, institutional change and economic performance. New York: Cambridge University Press.

Orszag, P. V. (2008). Health care and behavioral economics: a presentation to the National Academy of Social Insurance. Available online at (retrived at 2012-09-03) www.cbo.gov/sites/default/ files/cbofiles/ftpdocs/93xx/doc9317/05-29-nasi_speech.pdf.

Pauly, M. V., McGuire, T. G. and Barros, P. P. (Eds.) (2012). Handbook in Economics, Health Economics vol 2. London: North-Holland.

Pedersen, K. M. (2012). A new paradigm for health economics. Nordic Journal of Health Economics, 1(1): 17-27.

Pedersen, L. B., Kjaer, T., Kragstrup, J. and Gyrd-Hansen, D. (2012). Do general practitioners know patients' preferences? An experimental study of the agency relationship at an aggregate level using a discrete choice experiment. Value in Health. 15(3): 514-523.

Rabin. M. (1993). Incorporating fairness into game theory and economics. American Economic Review, 83: 1281-1302.

Schram, A. and Sonnemans, J. (2011). How Individuals Choose Health Insurance: An Experimental Analysis. European Economic Review, 55, 799-819.

Simon, H. A. (1955). A behavioral model of rational choice. Quarterly Journal of Economics, 69: 99-118.

Simon, H. A. (1956). Rational choice and the structure of the environment. Psychological Review, 63: $129-138$.

Smith J. (1999), Healthy Bodies and Thick Wallets: The Dual Relation between Health and Economic Status, Journal of Economic Perspectives, 13: 145-166.

Smith, V. L. (1991). Rational choice: the contrast between economics and psychology. Journal of Political Economy, 99(4): 877-897.

Stanovich, K. E. and West, R. F. (2000). Individual differences in reasoning: implications for the rationality debate? Brain and Behavioral Sciences, 23: 645-723.

Thaler, R. H. and Sunstein, C. R. (2008). Nudge: Improving Decisions About Health, Wealth, and Happiness. New Haven: Yale University Press.

Troëng, T., Weibull, H., Lyttkens, C. H., et al. (1997). Treatment decision for aortoiliac claudication - the current practice among Swedish vascular surgeons, European Journal of Surgery 163: 643-650.

Trottmann, M., Zweifel, P. and Beck, K. (2012). Supply-side and demand-side cost sharing in deregulated social health insurance: which is more effective? Journal of Health Economics, 31: 231-242.

Tversky, A. and Kahneman, D. (1992). Advances in prospect theory: cumulative representation of uncertainty. Journal of Risk and Uncertainty, 5: 297-323.

Wegwarth, O., Gaissmaier, W. and Gierenzer, G. (2009). Smart strategies for doctors and doctorsin-training. Heuristics in medicine. Medical Education, 43: 721-728.

(C) 2015 the author(s). This article is an open access article distributed under the terms and conditions of the Creative Commons Attribution license (http://creativecommons.org/licenses/by/4.0/). 